\title{
Reflections on the TV reception instance in the ambience of transmediality and interactivity
}

Alexandre Kieling*

DOI: https://doi.org/10.17230/9789587206289ch9

Amanda Caroline Rodrigues**

Kênia Freitas ***

\section{Introduction}

On November $17^{\text {th }}, 2016$, the analogical television signal was turned off in Brasilia (capital of Brazil) and in nine of its suburbs. This process is not new for the countries of the northern hemisphere; however, in a country with continental dimensions such as Brazil, it presents many structural, technical and social challenges. Therefore, this transition was closely followed by the Government and by the broadcasters. The major concern is the families that did not yet have televisions or converters capable of picking up the new signal.

It was from the necessity of empirical observation to understand this transition that our research group Studies of Transmedia and Interactive Digital Content created the project Migration to Digital TV. Its objective was to interview and observe families that went through this process of transition (from analogical to digital) on their televisions. We focused our field visits on households whose residents had received the antenna and the digital image converter from social programs and had recently installed them.

In this field of research, the immediate observation within the visited families was the perception and identification of at least three

* Bachelor in Social Communication from the Federal University of Santa Maria, Rio Grande do Sul, Brazil; Master's degree and Ph.D. in Communication Sciences from University of the Sinos River Valley, Rio Grande do Sul. Post doctorate in Applied Social Sciences from University of Brasília. Professor of the Masters Program in Communication at the Catholic University of Brasília. Email: alexandrek@ucb.br

"* Bachelor in Social Communication from the Catholic University of Brasília; Master's degree in Communication from the Catholic University of Brasília. Member of the Research Group on Transmedia and Interactive Digital Content's at the Catholic University of Brasília. Email: amanda.rodrigues.ucb@gmail.com

*** Bachelor in Social Communication from the Federal University of Espírito Santo; Master's degree in Multimedia from Campinas State University, Brazil. Ph.D. in Communication and Culture from Federal University of Rio de Janeiro. Post-doctoral researcher in Communication from the Catholic University of Brasília. Email: kenialice@gmail.com 
generational categories with quite different reception skills: adults older than 50, adults between the ages of 20 and 50, young people and children. In younger generations, we observed a relationship between the TV. and its integration with other media (especially with the internet), present in both the content chosen and in the way of watching it. In the older ones, we perceived interest in knowing and learning how to use the interactivity features integrated into the digital signal TV.

We believe that the perspective of mediations proposed by MartínBarbero (1997) remains fundamental for thinking about a communication scenario in which the technological transformations have intensified even more with their digitization process. Therefore, in this article we propose to analyze the displacements and new configurations of the television receiver figure from the places of mediation highlighted by Martín-Barbero: family daily life, social temporality and cultural competence.

Thus, we return to familiar everyday life -in spite of all new forms of consumption of television content -understanding that the family is still characterized as the basic unit of audience-, and a privileged space for the direct interaction of the spectators, a place of "reading and codification of television" (Martín-Barbero, 1997, p. 295). Simultaneously, we note and recognize a parallel process of everyday life virtualization by networks: the space in which television content is discussed and whereby it expands from the family unit in loco to the living spaces on-line, as the social networks.

As a consequence of this process, it is necessary to answer how much does the social temporality of viewers become manifest by their relationship with the programming grid, and in what ways this organizes the time of the viewer in the 21st century, as it did in the analog phase of Tv. The construction of social temporality in television passes through its genres, its exhibition times and the aesthetics of content repetition. Currently, we realize that social temporality seems to contemplate two times: the time of the present action and the time of network action. Concomitantly, this temporal organization is fragmented by the dispersion of content into other forms of distribution (such as streaming services: either video on demand or other internet distribution and access services). In these forms, the grid tends to cease to be the only way of temporal organization. We are faced, then, with the challenge of identifying these other types of social temporality that can be-or already are-created by the permanent supply of ideas and continuous content flow. 
It becomes inevitable to observe the dynamics of cultural competence. Supported by Martin-Barbero, it seems that this competence is linked to formal education, as well to habits, local and regional cultures, social and ethnic groups and their respective uses and customs. In the current context, this cultural competence incorporates practices and knowledge regarding the use of mobile devices and applications, suggesting consumption of hybrid and mestizo content. Such dynamics may result in the reconfiguration of the mediation space in the face of these cultural, social and technological dislocations.

In this analysis, we start with these initial observations to put in discussion, as a theoretical provocation, what the field has incited on us. Thus, we will investigate the reception skills which are at stake in the contemporary world, from the strengthening of a media convergence culture and the establishment of television as multiple media. We can set our initial concern from the following questions: When we think about television audience, to whom are we actually referring to? What distinguishes the various reception current instances: the viewer, the user, the audience, the consumer, the fan? And how can each of these instances be considered, from the television perspective? These are some of the issues that we will address in our communication.

\section{Background}

While the television technology was born as a unidirectional medium for audiovisual transmission, its functionalities and uses have been redefined over recent years, following the signal transition from analog to digital and the arrival of the Internet to TV. screens. At the end of the 20th century, theorists debated the passage from paleotelevision to neotelevision (Eco, 1986; Casseti \& Odin, 1990). Now, both terms have been superseded by a new television era, which combines digital technology, synchronism with other media and new formats and uses: the hypertelevision (Scolari, 2008).

Scolari proposed that this transformation is not only technological but also social, as spectators transfer their fruition experiences from other media to this new type of television. This hypertextual fruition experience engages spectators to interactivity and networking through fragmented textuality, and they become highly capable of adapting to new interaction media. This is the context digital television needs to adapt to. 
According to Orozco, this phenomenon created a new relationship between the audience and multiple screens, given new interactivity, media convergence and individualization capabilities (Orozco, 2010). Instead of spectators, there are users who dissolve classical styles of consumption and interaction with information and images. They are also viewers/internauts who insert themselves in the regular processes of production, circulation and reception, due to the profusion of digital devices (Kieling, 2009). The processes of recognition and circulation, according to Verón's social semiosis (Verón, 2004), are under intense and multidirectional flows. The television in the living room is not alone anymore, while the viewers sit down on armchairs and sofas to immerse themselves in audiovisual content.

Audiovisual mass consumption is currently under a paradigm dispute between fixed-grid and on-demand models. Furthermore, in Latin-American countries such as Brazil, the definitive migration from the analog to the digital signal is still under course. Viewers, users, producers and programmers are still discovering and building new possibilities, functionalities and uses for this hypertelevision.

\section{Results}

The reflections developed in this article depart from the field research carried out in 2016 in 56 family households that experienced the migration from analogue to digital television signals. In the homes visited, residents had received and installed reception kits from Digital TV. (a capture antenna, a signal converter and cables) after their registration in government social programs (Kieling, Rodrigues, \& Freitas, 2017, p. 158). Next, we present some of the answers about digital Tv. obtained through surveys applied in these houses. In the following section, we explain how these results are backed by the theoretical approach on the reception reconfiguration of the hypertelevision audience.

After summarizing the interviewees socioeconomic and educational characteristics, it was possible to determine that they have received a very basic education (where $50 \%$ had not finished elementary school), perceived a minimum wage income (or less) and were employed in service providing occupations, which do not require specific training. They, thus, belong to the most numerically significant population range in Brazil. 
In the country, this is the public who consume the most free of charge television programs.

As we explained in the beginning of this text, we identified three age / generational categories among our interviewees: elderly (adults over 60), adults (between 30 and 59 years old) and young (up to 29). The differences in communication habits among the three groups were evident. For example, we note that among the young, more than $90 \%$ have smartphones; and among the elderly, this number does not reach $42 \%$. We can argue, from the data found, that among the youngest, the relationship with television was more integrated with other media (cellular, internet), both in the content watched and in the devices used.

In relation to the transit to digital television, $100 \%$ of the respondents indicated that they had perceived its effects. Although everyone noticed the image improvements, it was only $57.1 \%$ of the interviewees who pointed out an alteration in the audio, and only the lowest $7.1 \%$ indicated interactivity as a differential factor; these last resource was in general unknown by the public. The numbers proved this perception: only $25 \%$ reported knowing what digital interactivity meant, and only $7.3 \%$ had already used some television interactivity features. Due to this absence, we decided to devote time for practical and theoretical demonstrations of the interactivity resources available in the Brazilian digital TV. system during the interviews.

It is important to add that the Brazilian terrestrial transmission system results from a combination of the Japanese audiovisual transmission system, IDB-T, and a Brazilian data transmission system called Ginga, developed by local researchers led by Rio de Janeiro's Catholic University. The Ginga middleware is adopted in Brazil and other 13 Latin-American countries.

Even though the demonstrations were made for the whole family, we soon we noticed that the children and adolescents ended up taking over the remote controls in place of their parents or older family members. Once again, the different layers of cultural competences present within the same family unit were evident while observing the interviewees interactions.

After these demonstrations, we inquired about their perception on possible uses of interactivity: $86.1 \%$ believe that interactive services can help families gain access to more information; $77.8 \%$ consider that they 
can help families with their rights, and $63.9 \%$ think that the interactivity tool can help families benefit more. The options "does nothing" or "it makes no difference on TV. were not marked. This indicates the interest that arose in the very act of our research, due to the demonstrations to access several resources.

If the interactivity resources in the newly acquired digital television were little known by the interviewees, we also investigated their use and knowledge of other devices connected to the digital communicative environment. Among the devices available at these homes, we found that $69.1 \%$ had smartphones; $43.6 \%$ cell phones without internet access; $29.1 \%$ desktop computers; $27.3 \%$ home telephones; $20 \%$ laptop computers and $3.6 \%$ had tablets. Regarding their use, the smartphone is at the top of the list, being used by $62.7 \%$ of the respondents on a daily basis, and the cell phone with no internet access follows second (used by 41.2\%). The order continues with computer desktops (21.6\%), home telephones (19.6\%) and, finally, laptops (5.9\%). Strangely, the tablet was not mentioned in the surveys.

Other numbers show that $83.9 \%$ of respondents reported having a cell phone. From this group, more than $85 \%$ are prepaid handsets and only $15 \%$ are postpaid. Additionally, $92.9 \%$ answered that they did not watch any TV. shows on the cell phone, but $77.8 \%$ stated that they would be interested in a cell phone model that would allow them to watch Tv. for free. Moreover, $71.4 \%$ answered that they use or have already used the internet. However, only $41.1 \%$ have internet at home, while the other $41.1 \%$ were not connected to the internet. From the first group, $23.2 \%$ said they were always connected, and $17.9 \%$, are connected only one or two hours a day. Thanks to these responses we realize that the uses of the network and mobile devices are still very limited for this population.

This explains why, among our interviewees, television continues to be the preferred medium for obtaining information. $92.7 \%$ of respondents indicated television news as their main source of information, followed by social networks, with $34.5 \%$. Also, printed newspapers (16.4\%), online newspapers (12.7\%) and print magazines (3.6\%) were pointed as their sources. A small group (7.3\%) indicated other forms, such as conversations with friends and neighbors.

When questioned about their interaction with other devices while watching Tv. half of the respondents said they never do it. However, the 
frequency of those who always or almost always interact while watching TV. reaches more than $30 \%$.

About $2 / 3$ of respondents feel like active participants rather than as passive viewers while they watch TV. To a great extent, the justifications mentioned emotional engagement with the programming content as a form of active participation. As for internet participation, the majority (75\%) consider themselves to be more active than passive -a slightly higher percentage than TV. (65\%), since they pointed out that they used the internet very often and that they were "talking" to others over the network. When asked if they felt any transformations as spectators after the transition from analog to digital, $78.8 \%$ answered affirmatively, by adding that the image improvement resulted in a greater programming engagement.

\section{Discussion}

What do these data show? On one hand, that this public does not possess a complete dominion of new technologies and media mixtures dimension; on the other, that there is the desire for inclusion in these virtual spaces. Social networking and messaging (especially WhatsApp and Facebook) are the most frequent gateways to accomplishing this. There is an evident access barrier and not exactly a spontaneous block to the process of digital alphabetization. The social dynamics of inclusion reveal the natural desire to be inserted and the material evidence of being excluded.

Therefore, we realized that the television content remains central to the mediation of social temporality of the respondents. Although there is an approximation, with virtualized environments on the internet and their own temporalities, the economic and cultural access barriers to the network media universe cannot be disregarded. Nevertheless, when these other temporalities are accessed, especially by the younger generations, we find uses that reinforce the processes of socialization, by the interpersonal connections of social networks. We realize that the resources offered by the Brazilian digital TV. system (such as interactivity and multiprogramming) have a great potential to connect the public with the techno-communicative environment, provided that these resources are made accessible, both in a financial way and in the dissemination of forms of use. 
Martín-Barbero seems to be precise once more, when he points out that television helps to mediate the time of life and the time "of denied, economically devalued and politically unknown sociability" (MartínBarbero 1997, p. 307). More than a desire or dream of inclusion in the techno-communicative environment, we perceive a strong necessity of such inclusion. In this context, it seems relevant to think of the reconfiguration of the mediation of cultural competence spaces based on the idea of dilution of devices, hybridization of genres and media confluence, in a scenario in which the television contents undergo processes of dissipation and incorporation between the multiple devices and media (Kieling, Freitas, \& Freitas, 2016).

We live in the age of convergence, an ever-present perspective in the course of the narratives and that has gained greater diffusion with the digitalization of the means of content distribution. Jenkins (2008) contributed to this process, as it explored the new forms of media consumption seeking to understand how these changes affected the way communication was done, especially by large producers. More than the prediction of a replacement of the old media by the new media, to which the theorists of the digital revolution of the 1990s subscribed, Jenkins argues that in the context of convergence, these old and new paradigms intersect and interact in increasingly complex ways. Thus, convergence occurs not only on multiple consumer platforms, but especially on the cognition of individual consumers and their social interactions (Jenkins, 2008, p. 30). For the author: "Convergence is, in this sense, an old concept assuming new meanings" (2008, p. 33). We realize, then, that in Jenkins, the key figure in reception is the consumer, the fan.

While Jenkins directs its analysis to the culture of convergence in a more marketing perspective, and how this new configuration interferes with the economic production of media conglomerates, Carlos Alberto Scolari points to the importance of shaping these new contents, and how the transmedia narratives adapt to passage through other means. According to Scolari (2008), the television transformation is provided by the new interactive media, and he questions how television narratives would fit the proposed interactivity. For the author, the approach changes because the reception instances change. In this sense, there is a need 
to adapt the traditional media to the new profile of viewers, who have new cognitive and perceptive skills. Thus, the proposal of interactive television distances itself from the television linearity, and makes the content available to the other platforms, fomenting hypertextual experiences. For Scolari, this new consumer profile / viewer anchors in other media experiences over television, and to attract this group, the TV. must pretend to be something it is not: an interactive medium. For Scolari, then, more than a matter of consumption or fan culture, what needs to be reconfigured is the TV. viewer's experience, which is changed by their experiences as users on other platforms.

Arlindo Machado brings the figure of the interactor to the discussion, as part of the change of status in the devices, in the audiovisual text and in the spectator on the new media (Machado, 2007, p. 133). Regarding the reception, what begins to change is the "viewer's agency". Thus, for Machado "everything that is going to unfold on the screen now depends on the decisions, actions and initiatives taken by the subject that relates to it, the computer user" (2007, p. 142). In this changing scenario, Machado uses the term interactor, since the expressions user, spectator, and receiver cannot account for the new participatory situations.

When we reflect about the results and observations of the field research, we realize that all these denominations are pertinent to analyze our group of respondents. In a general way, we perceive in interviewees the desire for accessibility and use of the new resources available through the digital TV. system and for integration with other connected communicative media. However, access to the media and its uses runs into barriers of economic and social exclusion: the use of the Internet is limited due to low incomes, and the use of resources is affected by a lack of technical knowledge.

The Jenkins consumer figure is determinant precisely because it includes the financial issues that cross reception and television production in the culture of convergence -although the author's approach is to think from the perspective of the big producers. In the field, as we have described, the barriers encountered by our interviewees were precisely to be able to assert themselves as active consumers. 
In relation to Scolari, we observe the new generations migration and adaptation movements as reconfigurations of the television reception by the contact with other communicational devices. On our field visits, the younger participants were more familiar with the interactivity features available on digital television, the ones who mostly used the internet and had other devices, such as smartphones. In relation to this new generation, they can be addressed as interactors, using the reconfiguration of reception, in terms of Machado. 


\section{Conclusion}

From the perspective of cultural competence, there was a latent digital exclusion in the case of recognition of television and technology texts, the audience perceptions of what they want and what they can do, what they need and what they know. These directly inhibit the convergence with the medio-sphere, connecting the production and reception instances with a negotiation of symbolic production and the generation of meaning.

From the data analysis obtained from the interviews and field observations, we identified five key points that emerge from this research (Kieling et al., 2017): i) The centrality and permanence of television; ii) The extensive transition process from open analogue to digital TV. signals in the Federal District and surroundings; iii) The significant access and knowledge barrier to digital media and technologies; iv) Although slow, there is a migration process into digital devices; and v) Interactivity is still a potentiality.

Martin-Barbero's reflection still fits well with the challenges of understanding these reconfigurations of techno-communication in the environment of media mixing, verifiable in the TV. digitalization and its convergence with mobile devices. His rich contribution supports on analysis and an approximation with the dynamics and the configurations of this mediatic ambience.

Nevertheless, it was possible to find clues to which aspects of everyday family life remain a mediation space and how this space can be updated or reconfigured, which highly rely on the universe of reception. They dissipate to other spaces and means that virtualize sociability. Even when viewers take on content-producing actions that circulate through social networks and experience the logic of that environment, they carry the links they see on television and add elements of their own day-to-day life. The sociability of the room expands into a virtual space.

The same movement is observed in social temporality. The rituality of TV. time, which is organized by programming and the hierarchy of genres (soap operas, news programs and auditorium programs) and by the 
viewer's social time, is now interspersed with the virtual time, the time to update the present. There is almost a complementary idea of presence and direct effects of TV. Convergence does generate new temporalities, but for the TV. audience they are associated with the divisions of working time, service time, and interaction time.

In a natural sequence of the phenomenon of digital immersion, the cultural skills accumulated with the years of consumption and television content literacy now serve as a practical basis for the assimilation and understanding of narratives and contents that are articulated with the digital environment. Television and mobile devices add new skills to understand technicity to the television audience, in a gradual and cumulative process to use and understand the language of digital machines. Even without having a fine mastery on computer grammars and their derivative devices, this audience is already embedded in digital confluence and the literacy process that understands the speech of chips.

In this research, we observed at least two trends: 1) Free broadcast television, far from being a disposable content distribution system, is a mean that has not been exhausted in its technological and economic possibilities; 2) The renewal of the conditions of production, circulation, and consumption -with TV. digitalization- ensures access to populations who still lack diverse connectivity options. Therefore, there is a possible social and cultural use.

It is a fact that there are indicators of a future trend centered on the distribution of content via fixed network infrastructures, and especially via mobile networks. Also, that the investments will be concentrated in areas of economic sustainability, as it can be seen nowadays in the distribution of global capital. It is hard to imagine that the content distribution will bypass the neoliberal rationality that assembles individual and planetary priorities. Therefore, it is in this complex scenario that is being established the logic of the viewer, the internaut and the user. There is a space where there is a belief on the existence of an interoperable platform and on the evolution of data distribution and terrestrial broadcast TV. interactivity. All this process seems to give us hints and indications not to turn the page in the studies and experiments with the Digital Terrestrial Interactive TV. 


\section{References}

Casetti, F., \& Odin, R. (1990). De la paléo- à la néo-télévision. Communications, (51), 9-26. Retrieved from https://bit.ly/2LExUrt Eco, U. (1986). TV: la transparencia perdida. In La estrategia de la ilusión. Barcelona, España: Lumen.

Jenkins, H. (2008). Cultura da Convergência. São Paulo, Brazil: Aleph. Kieling, A. S. (2009). Televisão: a presença do telespectador na configuração discursiva da interatividade no programa "Fantástico" (Doctoral thesis). São Leopoldo, University of the Sinos River Valley, Brazil.

Kieling, A. S., Freitas, E., \& Freitas, K. (2016). Apontamentos para compreender a TV líquida. In Dalvino, G., \& Bellicieri, F. (Orgs.). VI Seminário História de Roteiristas: entre encanto e conhecimento (pp. 250-259). São Paulo: Corpo e Texto.

Kieling, A., Rodrigues, A., Freitas, K. (2017). Digitalização da TV: cotidiano, sociabilidades e competências do telespectador. In Kieling, A. S., Freitas, K., \& Feitosa, D. (Orgs.), TV Digital: O desligamento do sinal analógico e a adaptação dos telespectadores (pp. 153-212). Brasíla: Universidade Católica de Brasília.

Machado, A. (2007). O sujeito na tela: modos de enunciação no cinema e no ciberespaço. São Paulo, Brazil: Paulus.

Martín-Barbero, J. (1997). Dos meios às mediações: comunicação, cultura e hegemonia. Rio de Janeiro, Brazil: Editora UFRJ.

Orozco, G. (2010). Audiencias y pantallas. Lo nuevo, lo viejo y lo que viene. En G. Cassano (Ed.), Televisión: 14 formas de mirarla (pp. 35-51). Lima, Perú: Departamento Académico de Comunicaciones PUC. Available in https://bit.ly/2s1ia9c

Scolari, C. (2008). Hacia la hipertelevisión. Los primeros síntomas de una nueva configuración del dispositivo televisivo. Diálogos de la Comunicación, (77), 1-9. Retrieved from https://bit.ly/2Q71ZmH

Verón, E. (2004). Fragmentos de um tecido (1st ed.). São Leopoldo, Brazil: UNISINOS. 